\title{
Antibiotic mediated synthesis of gold nanoparticles with potent antimicrobial activity and their application in antimicrobial coatings $\dagger$
}

\author{
Akhilesh Rai, ${ }^{a}$ Asmita Prabhune ${ }^{b}$ and Carole C. Perry ${ }^{* a}$ \\ Received 24th March 2010, Accepted 8th June 2010 \\ DOI: 10.1039/c0jm00817f
}

We report a one-pot synthesis of spherical gold nanoparticles $(52-22 \mathrm{~nm})$ and their capping with cefaclor, a second-generation antibiotic, without use of other chemicals. The differently sized gold nanoparticles were fabricated by controlling the rate of reduction of gold ions in aqueous solution by varying the reaction temperature $\left(20-70{ }^{\circ} \mathrm{C}\right)$. The primary amine group of cefaclor acted as both the reducing and capping agent for the synthesis of gold nanoparticles leaving the $\beta$-lactam ring of cefaclor available for activity against microbes. Antimicrobial testing showed that cefaclor reduced gold nanoparticles have potent antimicrobial activity against both Gram-positive (Staphylococcus aureus) and Gram-negative (Escherichia coli) bacteria as compared to cefaclor or gold nanoparticles alone. The minimum inhibition concentrations (MICs) of cefaclor reduced gold nanoparticles were $10 \mu \mathrm{g} \mathrm{mL}^{-1}$ and $100 \mu \mathrm{g} \mathrm{mL}^{-1}$ for $S$. aureus and E. coli respectively. The cefaclor reduced gold nanoparticles were further coated onto poly(ethyleneimine) (PEI) modified glass surfaces to obtain antimicrobial coatings suitable for biomedical applications and were tested against $E$. coli as an exemplar of activity. The antimicrobial coatings were very robust under adverse conditions ( $\mathrm{pH} 3$ and 10), inhibited the growth of $E$. coli on their surfaces, and could be used many times with retained activity. Results from a combined spectroscopic (FTIR) and microscopic study (AFM) suggest that the action of these novel particles is through the combined action of cefaclor inhibiting the synthesis of the peptidoglycan layer and gold nanoparticles generating "holes" in bacterial cell walls thereby increasing the permeability of the cell wall, resulting in the leakage of cell contents and eventually cell death.

\section{Introduction}

There is great interest in tailoring the size of nanomaterials to achieve unique chemical and physical properties with these materials having increasing importance in biological, ${ }^{1-3}$ biomedical, ${ }^{4,5}$ catalytic, ${ }^{6,7}$ optoelectronic ${ }^{8-10}$ and pharmaceutical $^{11,12}$ applications. For example, metal nanoparticles, magnetic nanoparticles and semiconductor quantum dots and their composite nanomaterials have been conjugated with small molecules such as DNA, drugs and proteins for delivery applications. ${ }^{13-16}$ Among drug molecules, many types of antibiotics are commercially available to combat Gram-positive and Gramnegative bacteria; however, the broad use of these antibiotics has caused bacteria to develop resistance against them. It is reported that bacteria have developed a new kind of $\beta$-lactamase that gives resistance against $\beta$-lactam antibiotics. ${ }^{17-19}$ Some approaches to overcome bacterial resistance have been developed such as to change the structure of $\beta$-lactam moiety of antibiotics ${ }^{20-22}$ and to synthesize new antibiotics of high efficiency ${ }^{23-26}$ although these methods are time consuming and are often not economically feasible.

${ }^{a}$ School of Science and Technology, Nottingham Trent University, Clifton Lane, Nottingham, NG, 11 8NS, UK. E-mail: carole.perry@ntu.ac.uk

${ }^{b}$ Biochemical Sciences Division, National Chemical Laboratory, Pune, 411008, India

$\uparrow$ Electronic supplementary information (ESI) available: TEM images of $\mathrm{NaBH}_{4}$ reduced gold nanoparticles, UV-vis spectra of gold nanoparticles, digital images of $S$. aureus and E. coli plates and FTIR spectra of gold-coated surfaces. See DOI: 10.1039/c0jm00817f
Many reports are available in the literature on the antimicrobial effect of antibiotics conjugated with different nanoparticles. ${ }^{27-32}$ Due to their large surface area to volume ratio and biocompatibility, inorganic nanoparticles are considered as ideal candidates for carrying large amounts of antibiotics without compromising their activity. ${ }^{\mathbf{1}-12}$ Additionally, antibiotics and inorganic nanoparticles are often used together as advanced antimicrobial agents due to their ability to act in concert, often having enhanced effectiveness. The advantage of using both antibiotics and inorganic nanoparticles together is that if bacteria have resistance against one of the components, a further component could kill them in a different manner. As examples, $\mathrm{Gu}$ et al. have reported the enhanced antimicrobial activity of vancomycin coated gold nanoparticles on vancomycin resistant enterococci (VRE). ${ }^{27}$ Similarly Grace and Pandian and Saha et al. have shown that coatings of aminoglycosidic antibiotics on gold nanoparticles have an antibacterial effect on a range of Gram-positive and Gram-negative bacteria. ${ }^{28,29}$ Li's group have shown the synergistic effect of the antibiotic (amoxicillin) with silver nanoparticles against Escherichia coli bacteria. ${ }^{30}$ Ciprofloxacin coated $\mathrm{SiO}_{2}{ }^{31}$ and lysozyme coated single walled carbon nanotubes (SWNTs) ${ }^{32}$ have also been used against microorganisms as antibacterial agents. However, the above-mentioned approaches require a large amount of the specific antibiotic and a sequence of multiple steps such as synthesis of nanoparticles followed by the functionalization of the surface and finally binding of antibiotics on the surface of nanoparticles is required before they can be used. To our knowledge, there is only one paper in the literature where an attempt has been made to 
synthesize quasi-spherical and anisotropic gold nanoparticles using the antibiotic cephalexin but the antibacterial effect of these particles was not studied. ${ }^{33}$ In this paper, we describe a single pot synthesis of spherical gold nanoparticles of different sizes using the $\beta$-lactam antibiotic, cefaclor, as both reducing and capping agent at a range of temperatures $\left(20^{\circ} \mathrm{C}\right.$ to $\left.70{ }^{\circ} \mathrm{C}\right)$ and describe their potent antimicrobial activity.

The modification of surfaces with antimicrobial agents to prevent the growth of harmful microorganisms has received much attention for application in biomedical devices and health as well as in the food and personal hygiene industries. Antimicrobial coatings are required to have antibacterial efficacy, ease of fabrication and low toxicity. Copper and copper alloy surfaces, ${ }^{34,35}$ bacteriophage modified surfaces, ${ }^{36}$ polymers, ${ }^{37-39}$ polycationic modified surfaces, ${ }^{40-42}$ photosensitiser coated surfaces $^{43,44}$ as well as silver and silver containing surfaces ${ }^{45,46}$ have been extensively used as antimicrobial coatings, albeit increasing exposure of these materials to microbes eventually leads to the increased occurrence of resistance to treatment. In our study, cefaclor reduced gold nanoparticles have been used to coat poly(ethyleneimine) (PEI) modified glass surfaces to obtain highly effective and robust antimicrobial coatings. This procedure might be useful for coating biomedical devices, ${ }^{47-49}$ implants, ${ }^{47-49}$ textile fibres for the treatment of wounds or burns $^{50,51}$ and glass windows and other surfaces to maintain hygienic conditions in the home, in hospitals and elsewhere.

\section{Experimental}

\section{Materials}

All chemicals ( $\mathrm{HAuCl}_{4}$, cefaclor $\left(\mathrm{C}_{15} \mathrm{H}_{14} \mathrm{ClN}_{3} \mathrm{O}_{4} \mathrm{~S},(6 R, 7 R)-7\right.$ $\{[(2 R)$-2-amino-2-phenylacetyl]amino $\}$-chloro-8-oxo-5-thia1-azabicyclo[4.2.0]oct-2-ene-2-carboxylic acid), sodium borohydride, and poly(ethyleneimine)) were purchased from Sigma Aldrich and used as received. All glassware were cleaned with soap solution followed by aqua regia $\left(1 \mathrm{~mL} \mathrm{HNO}_{3}\right.$ $(15.9 \mathrm{M}): 3 \mathrm{~mL}$ HCL $(12 \mathrm{M}))$ and rinsed with double-distilled water. Cellulose dialysis membrane $(10 \mathrm{kDa})$ was purchased from Spectrum Laboratory Inc. Staphylococcus aureus and $E$. coli cultures were used for the antibacterial study.

\section{Synthesis and characterization of nanoparticles}

An example synthesis is as follows. $100 \mu \mathrm{L}$ of $10^{-2} \mathrm{M}$ gold ions $\left(\mathrm{AuCl}_{4}^{-}\right)$were added to $9.8 \mathrm{~mL}$ water followed by the addition of $100 \mu \mathrm{L}$ of $10^{-2} \mathrm{M}$ cefaclor for the reduction of gold ions at different temperatures $\left(20-70{ }^{\circ} \mathrm{C}\right)$. Time dependent UV-vis spectra $(0-24 \mathrm{~h})$ were recorded using a Unicam UV2 UV-Vis spectrophotometer at resolution of $0.5 \mathrm{~nm}$ to monitor the reduction of gold ions. Transmission electron microscopy (TEM) measurements of the size and shape of gold nanoparticle samples were carried out on Jeol 2010 instrument operated at accelerating voltage of $200 \mathrm{kV}$. Samples for TEM measurements were prepared by placing a drop of the gold nanoparticle solution on carbon-coated copper grids and air-drying for $5 \mathrm{~min}$. After 5 min, any remaining solution was carefully removed by wicking with a tissue paper and the grids were left to dry completely at room temperature. A minimum of 100 particles was measured using ImageJ software. The size of gold nanoparticles synthesized at different temperatures was also measured by dynamic light scattering (DLS) using a Malvern Instrument (model Nano-S). Samples of gold nanoparticles for atomic force microscopy (AFM) were prepared by solution casting onto silicon wafers (111) to make thin films. These films were analysed in non-contact mode using a Pacific Nanotechnology Nano- $R_{2}$ instrument with $\mathrm{SiN}$ probes at a scan rate of $0.5 \mathrm{~Hz}$ in air.

The synthesized gold nanoparticle solutions were dialyzed using $10 \mathrm{kDa}$ cut-off cellulose membrane against double-distilled water for $24 \mathrm{~h}$. Before dialysis, the membrane was processed to remove any organic contamination according to the procedure suggested by the manufacturer. The dialyzed gold nanoparticles were frozen in liquid nitrogen and freeze-dried at $223 \mathrm{~K}$ using a Christ alpha freeze dryer. The binding of cefaclor to gold nanoparticles was analyzed by FTIR spectroscopy in transmission mode using a Nicolet Magna IR-750 spectrophotometer at $4 \mathrm{~cm}^{-1}$ resolution with 64 scans. $2 \mathrm{mg}$ of the dried powder (cefaclor reduced $\mathrm{Au}$ nanoparticles/cefaclor) were mixed with $198 \mathrm{mg} \mathrm{KBr}$ and pellatized at 10 tons pressure to make discs. Thermogravimetric analysis (TGA) of cefaclor reduced gold nanoparticles and cefaclor powder was performed using a Mettler-Toledo (TGA/SDTA851 ${ }^{\circ}$ ) instrument over a temperature range of $30-700{ }^{\circ} \mathrm{C}$ at a heating rate of $10{ }^{\circ} \mathrm{C} \mathrm{min}^{-1}$ in the presence of $\mathrm{N}_{2}$ gas.

\section{Antimicrobial activity testing}

S. aureus and E. coli were grown at $37^{\circ} \mathrm{C}$ and maintained on LB plates (Luria-Bertani broth with $1.5 \%$ agar). Bacteria were also grown in LB media for $24 \mathrm{~h}$ at $37^{\circ} \mathrm{C}$ and cell counts were quantified by $\mathrm{OD}_{590}$ measurements. Different amounts of cefaclor reduced gold nanoparticles and cefaclor $\left(10-500 \mu \mathrm{g} \mathrm{mL}^{-1}\right)$ as well as gold nanoparticles $\left(500 \mu \mathrm{g} \mathrm{mL}^{-1}\right)$ were added into bacterial suspensions $\left(10^{8} \mathrm{CFU} \mathrm{mL}^{-1}\right)$ and incubated for $6 \mathrm{~h}$ at $37{ }^{\circ} \mathrm{C} .100 \mu \mathrm{L}$ aliquots were taken out from the respective suspensions at $2 \mathrm{~h}$ intervals and diluted in saline to give $10^{3}$ bacteria per $\mathrm{mL}$ and plated on LB agar plates followed by incubation at $37{ }^{\circ} \mathrm{C}$. Colonies were visualized after $24 \mathrm{~h}$ and digital images of plates were captured. $100 \mu \mathrm{L}$ treated and untreated bacterial suspensions were dried to make films on $\mathrm{Si}$ wafers (111) and AFM measurements in non-contact mode were performed immediately. Cross-sectional analysis of AFM images was performed to understand the depth of holes formed in the treated bacteria.

\section{Film formation and antimicrobial study}

Glass slides were rigorously cleaned before use by submerging into piranha solution $\left(30 \% \mathrm{H}_{2} \mathrm{O}_{2}+70 \% \mathrm{H}_{2} \mathrm{SO}_{4}\right)$ for $1 \mathrm{~h}$. Subsequently they were washed with copious amounts of double distilled water. The washed glass slides were dipped in $5 \mathrm{mg} \mathrm{mL}^{-1}$ PEI solution for $12 \mathrm{~h}$ followed by washing with water to remove unbound PEI. PEI coated glass slides were treated with cefaclor reduced gold nanoparticle solution (synthesized at $20^{\circ} \mathrm{C}$ ) for $24 \mathrm{~h}$ to deposit gold films followed by drying using a stream of $\mathrm{N}_{2}$ gas. The deposition of gold nanoparticles was monitored as a function of time using UV-vis spectroscopy. Gold coated glass slides were dipped in $\mathrm{HCl}(\mathrm{pH} 3)$ and $\mathrm{KOH}(\mathrm{pH} 10)$ solutions and time dependent UV-vis spectra of slides were recorded to estimate the 
leaching of gold nanoparticles from the coated slides. To test antimicrobial activity of the treated gold slides, the treated gold slides (coated surface faced upward) and a plain glass slide were placed on LB agar plates and $100 \mu \mathrm{L}$ E. coli suspension were cultured and incubated at $37{ }^{\circ} \mathrm{C}$. The digital images of growing bacterial colonies were captured the next day. The same slides were removed from plates followed by washing with copious amounts of water and reused five times to check the reusability and remaining antimicrobial activity.

\section{Results and discussion}

The synthesis of gold nanoparticles by the reduction of aqueous gold ion solution $\left(10^{-4} \mathrm{M}\right)$ after exposure to cefaclor solution $\left(10^{-4} \mathrm{M}\right)$ at various temperatures $\left(20-70{ }^{\circ} \mathrm{C}\right)$ was followed by UV-vis spectroscopy. It is well known that gold nanoparticles exhibit a ruby red colour in aqueous solution due to the surface plasmon resonance (SPR) of metal nanoparticles. ${ }^{52}$ Fig. 1A shows UV-vis spectra of the aqueous gold nanoparticle solutions synthesized as a function of increasing temperature $\left(20-70{ }^{\circ} \mathrm{C}\right)$, spectra being recorded after completion of the reaction. The UVvis spectrum of gold nanoparticles synthesized at $20{ }^{\circ} \mathrm{C}$ clearly shows an intense surface plasmon resonance (SPR) band at $540 \mathrm{~nm}$ along with a small hump in a range from 620 to $750 \mathrm{~nm}$ (curve 1, Fig. 1A). The presence of the small hump could be due to the formation of a small population of triangular nanoparticles. ${ }^{52}$ Supporting evidence for this observation was obtained by TEM analysis of nanoparticles from this solution
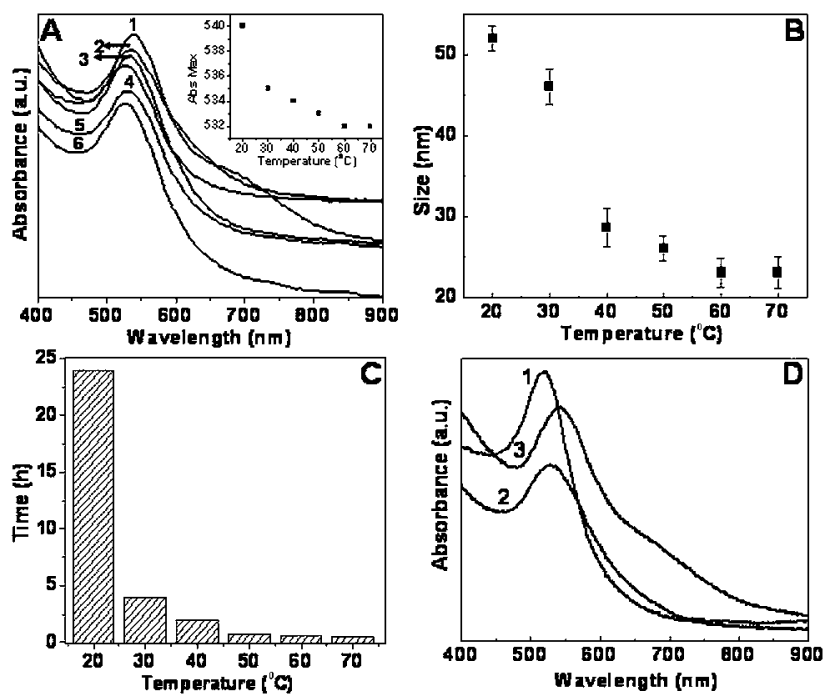

Fig. 1 (A) Representative UV-vis spectra of gold nanoparticles synthesized using cefaclor at $20^{\circ} \mathrm{C}$ (curve 1 ), $30^{\circ} \mathrm{C}$ (curve 2), $40^{\circ} \mathrm{C}$ (curve 3), $50{ }^{\circ} \mathrm{C}$ (curve 4 ), $60{ }^{\circ} \mathrm{C}$ (curve 5) and $70{ }^{\circ} \mathrm{C}$ (curve 6). Inset shows the absorbance maxima of curves 1-6 vs. temperature. The absorption maxima of the gold nanoparticle spectra were determined after spectra were smoothed (11 point adjacent averaging) and the derivative spectra obtained (Origin software). (B) DLS data, the size of gold nanoparticles versus temperature. (C) Maximum time for the complete reduction of gold ions using cefaclor at different temperatures. (D) UV-vis spectra of gold nanoparticles synthesized using $\mathrm{NaBH}_{4}$ (curve 1), after binding of cefaclor to $\mathrm{NaBH}_{4}$ reduced gold nanoparticles (curve 2) and the gold nanoparticles synthesized using cefaclor at $20^{\circ} \mathrm{C}$ (curve 3 ).
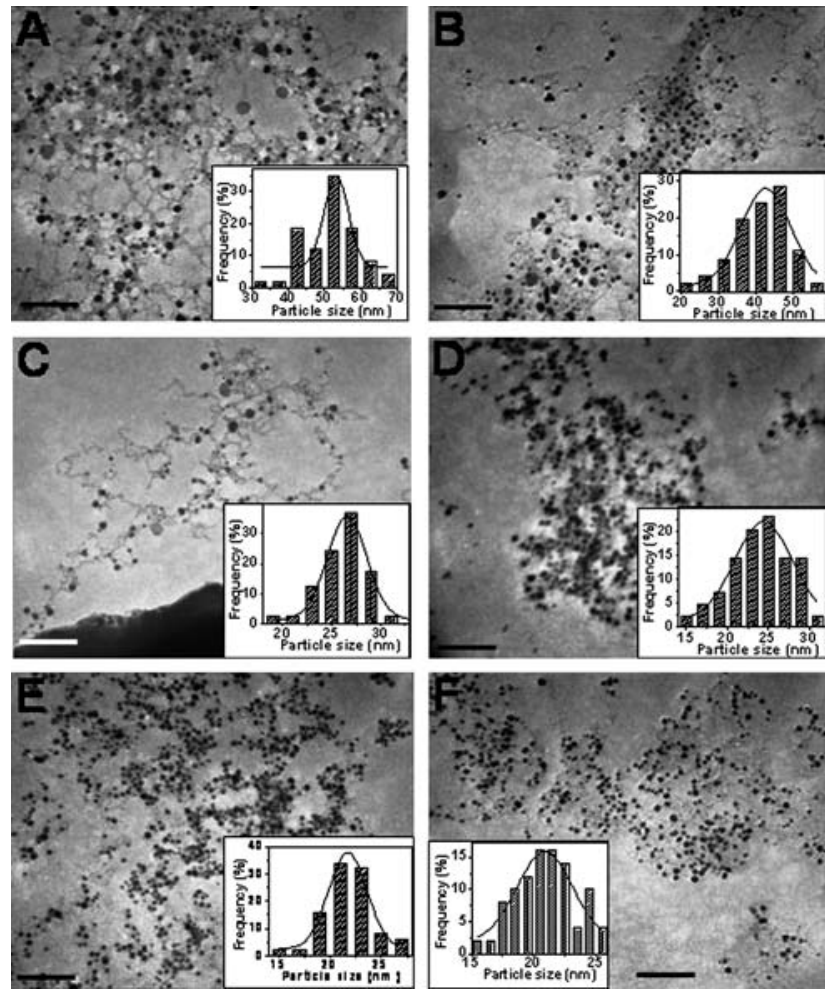

Fig. 2 Representative TEM images of the gold nanoparticles synthesized at $20{ }^{\circ} \mathrm{C}(\mathrm{A}), 30^{\circ} \mathrm{C}(\mathrm{B}), 40^{\circ} \mathrm{C}(\mathrm{C}), 50^{\circ} \mathrm{C}(\mathrm{D}), 60^{\circ} \mathrm{C}$ (E) and $70{ }^{\circ} \mathrm{C}$ (F). Scale bar presented in TEM images (A-F) is $200 \mathrm{~nm}$. Insets show particle size distributions of gold nanoparticles at different temperatures. Different bin sizes were used to obtain information on the size distribution of the particles appropriate to the samples investigated.

(Fig. 2A). Curves 2-6 correspond to UV-vis spectra of gold nanoparticles synthesized at $30,40,50,60$ and $70^{\circ} \mathrm{C}$ respectively. A comparison of the spectra showed that as the temperature increased, the surface plasmon resonance (SPR) band blue shifted monotonically to lower wavelength from 540 at $20{ }^{\circ} \mathrm{C}$ to $532 \mathrm{~nm}$ at 60 and $70^{\circ} \mathrm{C}$ (Fig. 1A, inset). The blue shift in the SPR band is symptomatic of a reduction in the size of gold nanoparticles synthesized with increasing temperature. The similar effect on the size of triangular gold nanoparticles synthesized using a biological approach has also been observed by Sastry's group. ${ }^{53,54}$ This result is also in agreement with TEM images and DLS analysis of gold nanoparticles synthesized using cefaclor in this study that show a decrease in size of nanoparticles from $52 \pm 1.5 \mathrm{~nm}$ to $23 \pm 2 \mathrm{~nm}$ with increasing temperature from 20 to $60{ }^{\circ} \mathrm{C}$ of the reaction solution (Fig. 1B and 2, insets). The particle size distribution of gold nanoparticles using TEM images correlates well with the DLS analysis. TEM images clearly show the presence of a few triangular nanoparticles produced in the lower temperature reaction solutions $\left(20-40^{\circ} \mathrm{C}\right)$ due to the slow reduction of gold ions using cefaclor (Fig. 2A). ${ }^{53,54}$ Interestingly, there is no change in the SPR band position and the size of gold nanoparticles synthesized at 60 and $70{ }^{\circ} \mathrm{C}$, indicating that saturation of gold ion $\left(\mathrm{AuCl}_{4}^{-}\right)$reduction using cefaclor has been reached by $60{ }^{\circ} \mathrm{C}$ (Fig. $1 \mathrm{~A}$ and 2).

The synthesis of gold nanoparticles using cefaclor at different temperatures $\left(20-70^{\circ} \mathrm{C}\right)$ was followed as a function of time by 
UV-vis spectroscopy (raw data not shown). The results are shown as a time vs. temperature plot (Fig. 1C). The reduction of gold ions $\left(\mathrm{AuCl}_{4}{ }^{-}\right)$using cefaclor was completed after $24 \mathrm{~h}$ of reaction in solution at $20^{\circ} \mathrm{C}$. A drastic reduction in the time of gold ion reduction was observed when the reaction was performed at higher temperatures. With increasing temperatures from 30 to $70{ }^{\circ} \mathrm{C}$, the reaction time was reduced to $4 \mathrm{~h}$ and finally to $30 \mathrm{~min}$ respectively (Fig. 1C). It is well known that amine groups can easily protonate in acidic or neutral solution and transfer electrons to gold ions $\left(\mathrm{Au}^{3+}\right)$, leading to the formation of $\mathrm{Au}^{0}$ (nuclei)/ $\mathrm{Au}$-amine complexes via simple amine chemistry. ${ }^{55-60}$ The synthesis of gold nanoparticles of different sizes is a kinetically driven process. ${ }^{54}$ Increasing the reaction temperature during the reduction of gold ions $\left(\mathrm{AuCl}_{4}{ }^{-}\right)$using cefaclor leads to an increase in the rate of reduction of the gold ions, which promotes an enhanced nucleation rate with the formation of a large population of nuclei. ${ }^{61-63}$ Gold ions are further reduced on the surface of gold nuclei, thus promoting the formation of spherical gold nanoparticles of smaller sizes, which are subsequently capped and stabilized by cefaclor (Scheme 1). ${ }^{59} \mathrm{Within}$ another possible threestep growth mechanism, gold nuclei $(2 \mathrm{~nm})$ first form bigger particles $(4 \mathrm{~nm})$ through coalescence ${ }^{64}$ or Oswald ripening. ${ }^{65}$ The second stage comprises the slow growth of particles by diffusion of reduced gold precursors. In the final stage, the particles from the second stage again coalesce and particles grow to their final size, the size being dependent on the complete consumption of gold ions or reducing agents (Scheme 1) ${ }^{66}$ An increase of reaction temperature causes each phase of the reaction to proceed faster, leading to the formation of smaller gold nanoparticles. The increase in formation rate suggests that the reduction rate of gold ions is a critical factor that determines the size of nanoparticles in this system.

UV-vis spectra of $\mathrm{NaBH}_{4}$ reduced gold nanoparticles and cefaclor bound to $\mathrm{NaBH}_{4}$ reduced gold nanoparticles are shown in Fig. 1D. Curve 1 corresponds to $\mathrm{NaBH}_{4}$ reduced gold nanoparticles and shows a sharp SPR band with an absorbance maximum at $520 \mathrm{~nm}$, indicating the formation of monodisperse gold nanoparticles, which is in agreement with TEM analysis (Fig. S1A, ESI $\dagger$ ). The red shift of $7 \mathrm{~nm}$ with respect to curve 1

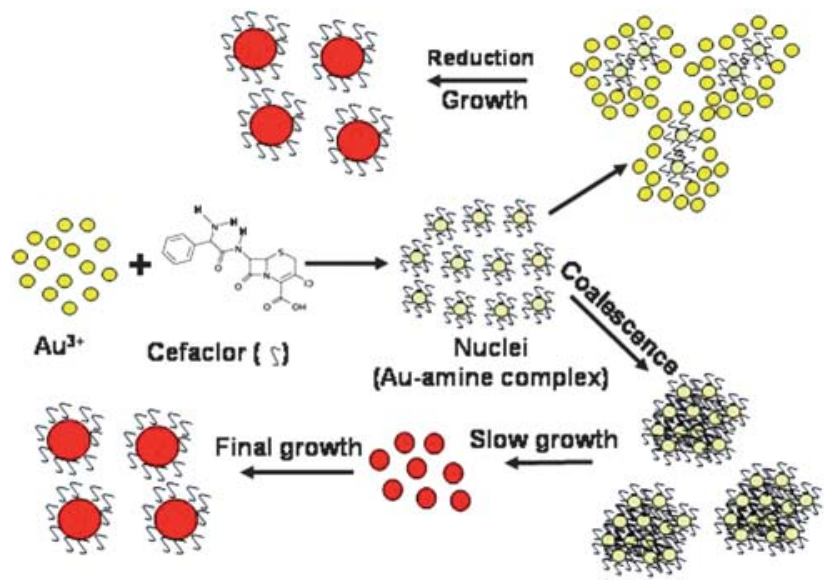

Scheme 1 Schematic representation of two possible mechanisms for the synthesis of gold nanoparticles. It should be noted that the scheme is not to scale. and a broad SPR band centred at $528 \mathrm{~nm}$ (curve 2) can be attributed to the surface modification of $\mathrm{NaBH}_{4}$ reduced gold nanoparticles using cefaclor and the formation of a small population of aggregated gold nanostructures in solution as also observed using TEM analysis (Fig. S1B $†$ ). The nature of curve 3 (corresponds to the gold nanoparticles synthesized using cefaclor at $20^{\circ} \mathrm{C}$ ) differs from curves 1 and 2, suggesting that the synthesis method using cefaclor at $20^{\circ} \mathrm{C}$ produces a small population of triangular gold nanoparticles in addition to spherical particles as discussed above (Fig. 2A).

Solutions of cefaclor reduced gold nanoparticles at different temperatures had a long-term stability and showed no sign of aggregation even after storage for six months. Such long-term stability of the gold nanoparticles indicated that nanoparticles were well bound with cefaclor. Cefaclor bound on the surface of the gold nanoparticles did not show an increase in intensity of signal at $c a .264 \mathrm{~nm}$ in the $\mathrm{UV}$ region, characteristic of cefaclor, indicating no leaching of cefaclor from the surface of the gold nanoparticles (Fig. S2A $\dagger$ ). ${ }^{67-69}$ The freeze-dried powder of gold nanoparticles synthesized at different temperatures were easily redispersed in water after ultrasonication for $15 \mathrm{~min}$, showing stability and easy storage of cefaclor bound gold nanoparticles in the form of a powder (Fig. S2B $\dagger$ ).

The cefaclor bound gold nanoparticles were analyzed by thermogravimetric analysis (TGA) in order to obtain quantitative information on cefaclor content. The initial $1.5 \%$ to $8 \%$ weight loss in temperature region of 30 to $200{ }^{\circ} \mathrm{C}$ is due to desorption of water molecules from the surface of the gold nanoparticles (Fig. 3A). A total weight loss $(100 \%)$ of cefaclor was observed in multiple distinct steps until $660^{\circ} \mathrm{C}$ (curve 1) with initial gradual and then rapid loss at higher temperature. TGA data of cefaclor reduced gold nanoparticles synthesized at 20, 40 and $70{ }^{\circ} \mathrm{C}$ show 60,57 and $52 \%$ weight loss, respectively, of cefaclor in three distinct steps of weight losses at 200 to $276^{\circ} \mathrm{C}$, 276 to $470{ }^{\circ} \mathrm{C}$ and 470 to $660^{\circ} \mathrm{C}$ temperature regions respectively (curves 2-4, Fig. 3A and B). From TGA measurements, it was confirmed that a larger amount of cefaclor was used in the reduction of gold ions and subsequent binding to the gold nanoparticles during synthesis and post-synthesis at $20^{\circ} \mathrm{C}$ than at higher temperatures (Fig. 3A and B). The formation of larger gold nanoparticles requires more gold nuclei/ $\mathrm{Au}$-amine complexes to coalesce to form the final gold nanoparticles, which mirrored a higher loading of cefaclor on the gold nanoparticles synthesized at $20^{\circ} \mathrm{C}$ (Fig. 3A and B). We suggest that the slow rate of reduction at $20{ }^{\circ} \mathrm{C}$ also provides a long-time for the interaction of cefaclor with gold nanoparticles in the reaction solution, leading to the binding of a large amount of cefaclor. The three distinct weight losses at three different temperature regions indicate that there may be three different modes of interaction between cefaclor and gold nanoparticles. ${ }^{70,71} \mathrm{~A}$ small amount of weight loss in the lower temperature region is suggestive of the physical adsorption of cefaclor on the surface of gold nanoparticles via rearrangement of bound cefaclor molecules. ${ }^{70}$ The maximum weight loss in the 276 to $470{ }^{\circ} \mathrm{C}$ region is a result of the covalent interaction of an amine group with the gold nanoparticles, indicating that higher energy is required to decompose/desorb the cefaclor from gold nanoparticles. ${ }^{71}$ The third loss at higher temperature region $\left(515\right.$ to $\left.660{ }^{\circ} \mathrm{C}\right)$ is most likely due to the electrostatic interaction of the amine group of 


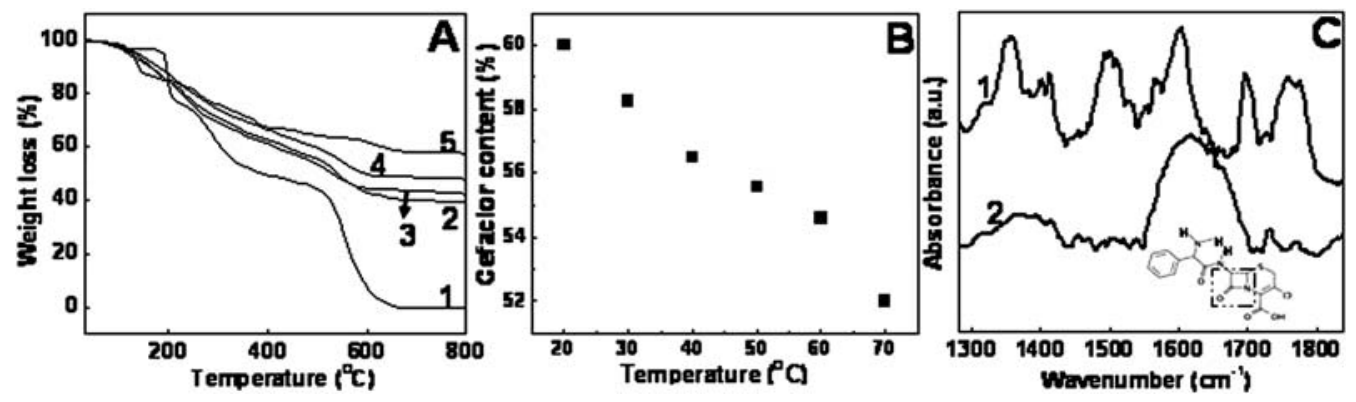

Fig. 3 (A) TGA analysis of cefaclor (curve 1), cefaclor reduced gold nanoparticles at $20^{\circ} \mathrm{C}$ (curve 2), $40{ }^{\circ} \mathrm{C}$ (curve 3 ), $70{ }^{\circ} \mathrm{C}$ (curve 4 ) and cefaclor bound on $\mathrm{NaBH}_{4}$ reduced gold nanoparticles (curve 5). (B) TGA analysis of cefaclor content (\%) in the gold nanoparticles synthesized at different temperatures. (C) FTIR measurement of cefaclor (curve 1) and cefaclor reduced gold nanoparticles at $20^{\circ} \mathrm{C}$ (curve 2). An inset shows the chemical structure of cefaclor. The square in the chemical structure indicates the $\beta$-lactam ring of the antibiotic.

cefaclor with negatively charged $\mathrm{AuCl}_{4}^{-}$ions present on the surface of gold nanoparticles. Gold is known to bind strongly with organic molecules containing amine groups. ${ }^{72,73}$ TGA data suggest that after being electrostatically attached to gold nanoparticles, cefaclor binds to gold nanoparticles through covalent and physical interactions. Curve 5 shows a $42 \%$ weight loss for cefaclor bound on $\mathrm{NaBH}_{4}$ reduced gold nanoparticles, which is less than the weight loss of cefaclor reduced gold nanoparticles, indicating the weaker interaction of cefaclor to gold surfaces.

To complement the TGA data, Fourier transform infrared (FTIR) spectroscopy was performed to analyze the binding of cefaclor on the surface of gold nanoparticles. Curve 1, Fig. 3C, shows the characteristic FTIR spectrum of cefaclor with bands at $1770 \mathrm{~cm}^{-1}(\mathrm{C}=\mathrm{O}$ group of four membered ring lactams and $\mathrm{COOH}$ functional group), $1697 \mathrm{~cm}^{-1}\left(\mathrm{C}=\mathrm{O}\right.$ group), $1605 \mathrm{~cm}^{-1}$ (primary amine), $1505 \mathrm{~cm}^{-1}\left(\mathrm{C}=\mathrm{C}\right.$ ring stretch) and $1415 \mathrm{~cm}^{-1}$ $\left(\mathrm{C}-\mathrm{N}\right.$ stretch). ${ }^{74-76}$ The characteristic $\beta$-lactam ring vibrations were also observed at 1418,1395 and $1357 \mathrm{~cm}^{-1}$ in curve 1 , Fig. 3C, as suggested by Gil et al..$^{76}$ The band at $1625 \mathrm{~cm}^{-1}$ for cefaclor reduced gold nanoparticles (curve 2, Fig. 3C) could be assigned to an amine group, which is shifted to a higher wavenumber compared to the primary amine of pure cefaclor $\left(1604 \mathrm{~cm}^{-1}\right)$, indicating that the primary amine group of cefaclor acts as the reducing and capping agent for the synthesis of gold nanoparticles. Other FTIR bands corresponding to different functional groups and the $\beta$-lactam ring of cefaclor reduced gold nanoparticles (curve 2) do not show shifts in band positions compared to the FTIR spectrum of the plain cefaclor (curve 1, Fig. 3C). It could be inferred from this result that the $\beta$-lactam ring, which is responsible for antimicrobial activity of cefaclor, is present in free form on the surface of gold nanoparticles (an inset of Fig. 3C).

After characterization of cefaclor bound gold nanoparticles using various techniques, gold nanoparticles synthesized at $20{ }^{\circ} \mathrm{C}$, due to the high loading of cefaclor on the surface of the nanoparticles, were tested for antibacterial activity against Gram-positive (S. aureus) and Gram-negative (E. coli) bacteria. All antibacterial activity tests were performed in triplicate and were performed at different times to certify the reproducibility of behaviour. $10 \mu \mathrm{g} \mathrm{mL}^{-1}$ to $500 \mu \mathrm{g} \mathrm{mL}^{-1}$ cefaclor bound gold nanoparticle solutions were added to $S$. aureus and $E$. coli suspensions and were incubated for $24 \mathrm{~h}$ at $37^{\circ} \mathrm{C}$. Antibacterial kinetics was analyzed by plotting colony forming unit (CFU) versus incubation time, which provides evidence for the effectiveness of the nanomaterials (Fig. 4). As the incubation time increases, CFU of the bacterial population (S. aureus) decreased with increasing amount of cefaclor bound gold nanoparticles.

Fig. 4A showed that after $4 \mathrm{~h}$ of incubation, no bacterial colony ( $S$. aureus) was observed for the lowest concentration $\left(10 \mu \mathrm{g} \mathrm{mL}^{-1}\right)$ of cefaclor reduced gold nanoparticles although $200 \mu \mathrm{g} \mathrm{mL} \mathrm{m}^{-1}$ cefaclor reduced gold nanoparticles was adequate to kill most bacteria $(99 \%)$ in $2 \mathrm{~h}$. In contrast, a small population of bacteria (32 CFU) compared to the control ( $320 \mathrm{CFU}$ ) was observed for a $10 \mu \mathrm{g} \mathrm{mL}^{-1}$ concentration of cefaclor after $4 \mathrm{~h}$,
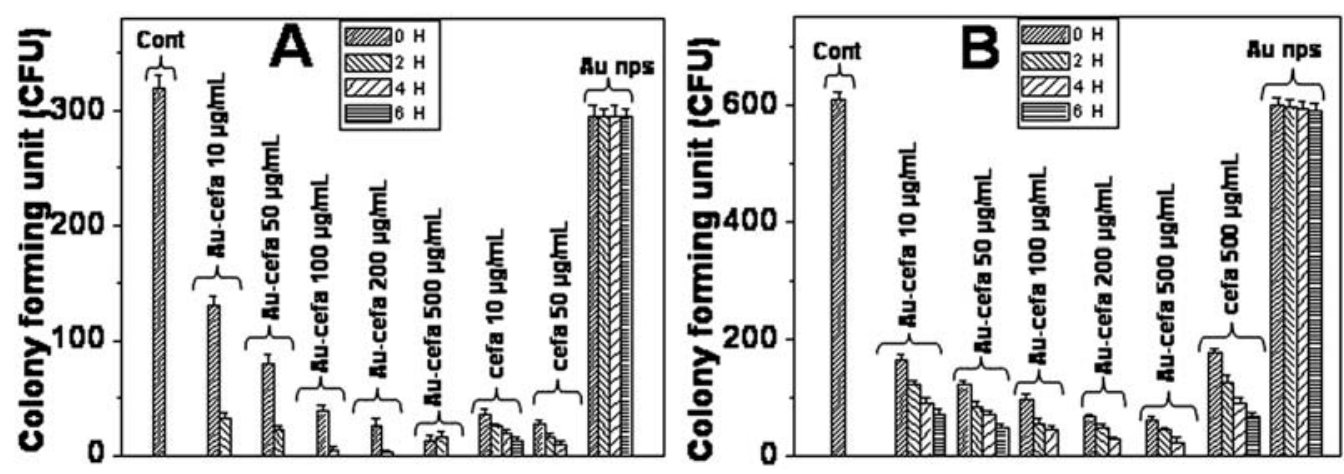

Fig. 4 Histogram plot showing antimicrobial activity of cefaclor reduced gold nanoparticles, gold nanoparticles and cefaclor on $S$. aureus (A) and E. coli bacteria (B) after different times of incubation at $37^{\circ} \mathrm{C}$. 
indicating a slow rate of inhibition of bacterial growth as compared to the result obtained with the cefaclor reduced gold nanoparticles (Fig. 4A). No bactericidal activity was observed for $500 \mu \mathrm{g} \mathrm{mL}^{-1}$ gold nanoparticles without cefaclor (Fig. 4) most likely due to the presence of a peptidoglycan layer on cell wall of $S$. aureus that does not allow the penetration of gold nanoparticles. The images of bacterial growth with increasing incubation time and increasing concentration of cefaclor bound gold nanoparticles are shown in Fig. S3.† The minimum time required to inhibit the complete growth of $S$. aureus in solution using cefaclor was $6 \mathrm{~h}$. The MIC (minimum inhibition concentration) is defined as the lowest concentration $\left(\mu \mathrm{g} \mathrm{mL}^{-1}\right)$ of drug that inhibits visible growth of microorganisms on the culture plate. $^{77}$ The MICs of Gram-positive bacteria ( $S$. aureus) obtained from cefaclor reduced gold nanoparticles and cefaclor were $10 \mu \mathrm{g} \mathrm{mL}^{-1}$ and $50 \mu \mathrm{g} \mathrm{mL}^{-1}$ respectively (Fig. 4A). A lower MIC corresponds to a higher antibacterial effectiveness, indicating the superior antimicrobial activity of cefaclor reduced gold nanoparticles than cefaclor or gold nanoparticles alone. A single gold nanoparticle, having a high surface to volume ratio, would contain a large number of cefaclor molecules, acting as a single group against bacteria. Perhaps this is the reason that cefaclor reduced gold nanoparticles rather than cefaclor are more potent antimicrobial agents against bacteria. Cefaclor, as a second-generation antibiotic of the cephalosporin family, has the same mode of antibacterial action as other $\beta$-lactam antibiotics by disrupting the synthesis of the peptidoglycan layer of bacterial cell walls. Cefaclor interacts strongly with the outer peptidoglycan layer of Gram-positive bacteria, resulting in the loss of membrane integrity along with the development of pores on the cell wall, as evidenced by AFM analysis (Fig. 5A and D). The presence of pores in the cell wall leads to increased permeability, leakage of the cell contents and ultimately cell death.

A height mode AFM image shows that the cell wall structure of $S$. aureus changed significantly after treatment with cefaclor reduced gold nanoparticles (Fig. 5B). The cell wall was observed to be severely damaged and punctured after treatment while a smooth cell wall of $S$. aureus is observed in the control experiment (without exposure to cefaclor reduced gold nanoparticles) (Fig. 5C). The origin of the "holes" in the cell wall can be described as fissures, which are formed due to the penetration of gold nanoparticles through a porous membrane. The "holes" in the AFM images are observed due to the free movement of damaged membrane as compared to the surrounding intact structure when force is applied on them by the AFM tip during scanning. ${ }^{78}$ The formation of grooves and pore-like lesions as well as the collapse of cell wall structures can also be seen after treatment with both cefaclor and cefaclor reduced gold nanoparticles in contrast to the uniform cell wall of $S$. aureus (without treatment) in the phase mode AFM images (Fig. 5D-F). The leakage of a substantial amount of the cell contents from damaged cells can be found around the bacterial cell as assessed
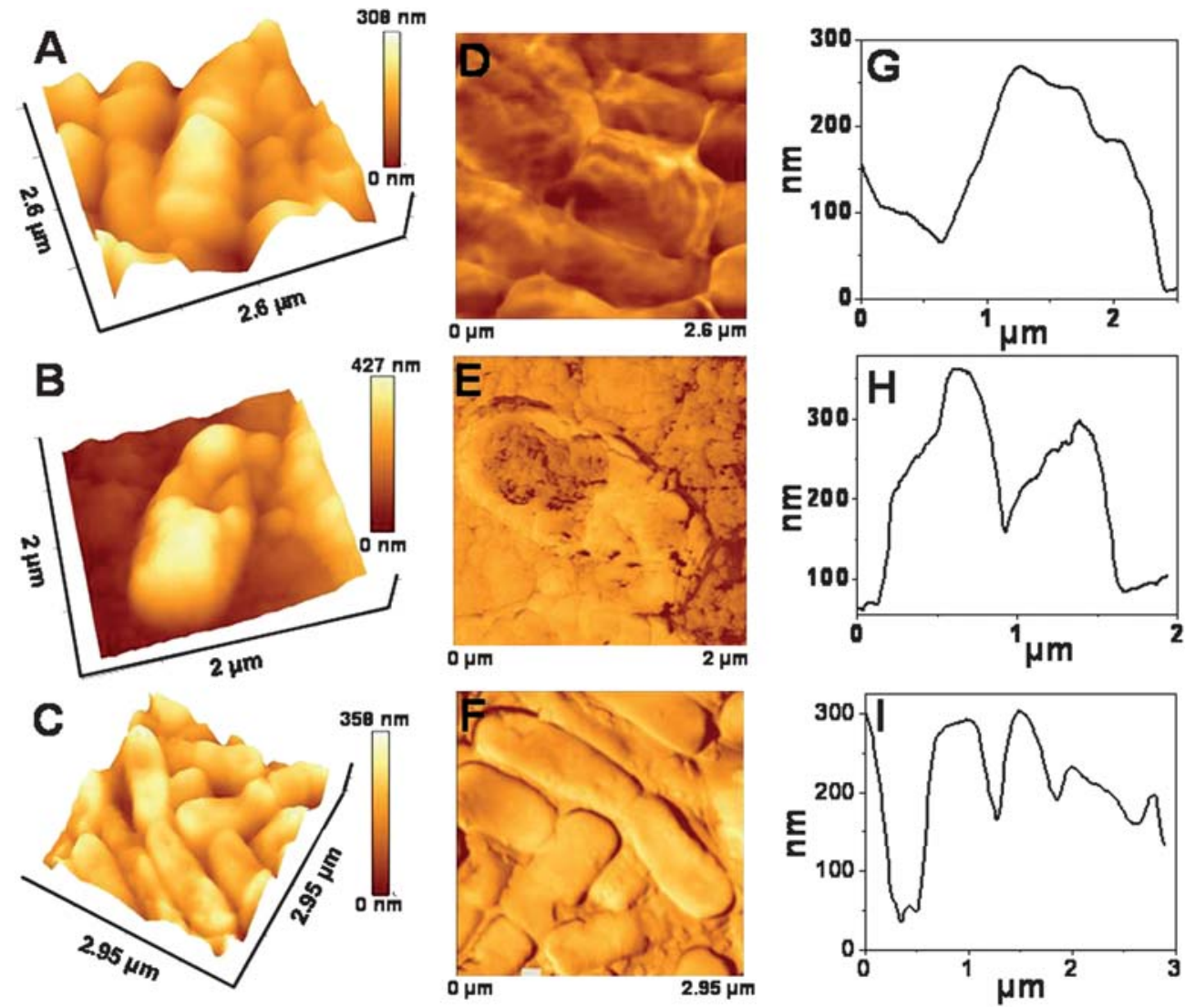

Fig. 5 Representative height mode AFM images of S. aureus treated with cefaclor (A), S. aureus treated with cefaclor reduced gold nanoparticles (B) and plain $S$. aureus without the treatment (C). Phase mode images (D-F) and cross-sectional analysis (G-I), of the corresponding height mode images (A-C). 
in both height and phase mode images (Fig. 5). Other researchers have also observed the same features in AFM images of antibacterial peptide damaged bacteria. ${ }^{79}$ In the phase images it was clearly visible that the outer rigid peptidoglycan layer of the cell was almost intact after treatment (Fig. 5D-F). However, crosssectional analysis reveals that the smoothness, roughness and height of the cell wall have changed dramatically (Fig. 5G-I). The damaged cell shows increased roughness with decreased height due to the collapsed cell wall compared to that of the smooth surface of $S$. aureus (without treatment) in AFM imaging mode and as assessed by cross-sectional analysis (Fig. 5). It can also be observed in cross-sectional analysis that pores on the surface of cefaclor reduced gold nanoparticle treated bacteria are much deeper than those on cefaclor treated bacteria (Fig. 5G and $\mathrm{H}$ ).

It is also important to observe the antimicrobial effect of cefaclor reduced gold nanoparticles and cefaclor on Gramnegative bacteria that have a thin peptidoglycan layer adjacent to the inner cytoplasmic membrane, which makes them have little resistance against cefaclor. In case of $E$. coli, a longer incubation time of $6 \mathrm{~h}$ with $100 \mu \mathrm{g} \mathrm{mL}^{-1}$ cefaclor reduced gold nanoparticles was required to inhibit the complete growth of bacteria in culture media (Fig. 4B and $\mathrm{S} 4 \dagger$ ). The MIC of cefaclor reduced gold nanoparticles on $E$. coli is $100 \mu \mathrm{g} \mathrm{mL}^{-1}$, which is ten times higher than the MIC of $S$. aureus. There is a gradual decrease in the population of $E$. coli with increasing doses and incubation time (Fig. 4B and $\mathrm{S} 4 \dagger$ ). Interestingly, $500 \mu \mathrm{g} \mathrm{mL}^{-1}$ gold nanoparticles showed a weak bactericidal activity (10\%) with $90 \%$ survival. Cefaclor alone $\left(500 \mu \mathrm{g} \mathrm{mL}^{-1}\right)$ did not show $100 \%$ growth inhibition after $6 \mathrm{~h}$ of incubation in contrast to the total growth inhibition $(100 \%)$ of $S$. aureus by cefaclor after a similar incubation time (Fig. 4). This result indicates that cefaclor bound gold nanoparticles have superior antibacterial activity over both cefaclor and gold nanoparticles on Gram-negative bacteria. AFM analysis (Fig. 6A) showed that distinct holes were formed on the surface of the bacteria along with highly roughened cell walls due to disruption of the cell wall integrity after treatment with cefaclor reduced gold nanoparticles.

The formation of holes in the membrane leads to leakage of the cell contents and death of the bacteria. Gold nanoparticles embedded inside the bacterial membrane (marked by arrows) as well as protrusions of the membrane can also be observed in AFM images (Fig. 6A). A phase mode AFM image (Fig. 6E) clearly demonstrates different sizes of embedded gold nanoparticles at three places that are covered by the cell contents and damaged membranes, indicating the penetration depth of gold nanoparticles at that time, in agreement with data from the crosssectional analysis (Fig. 6I). The AFM images (height and phase modes) of cefaclor treated bacteria (Fig. 6B and F) show a highly roughened surface along with the presence of leaked cell contents
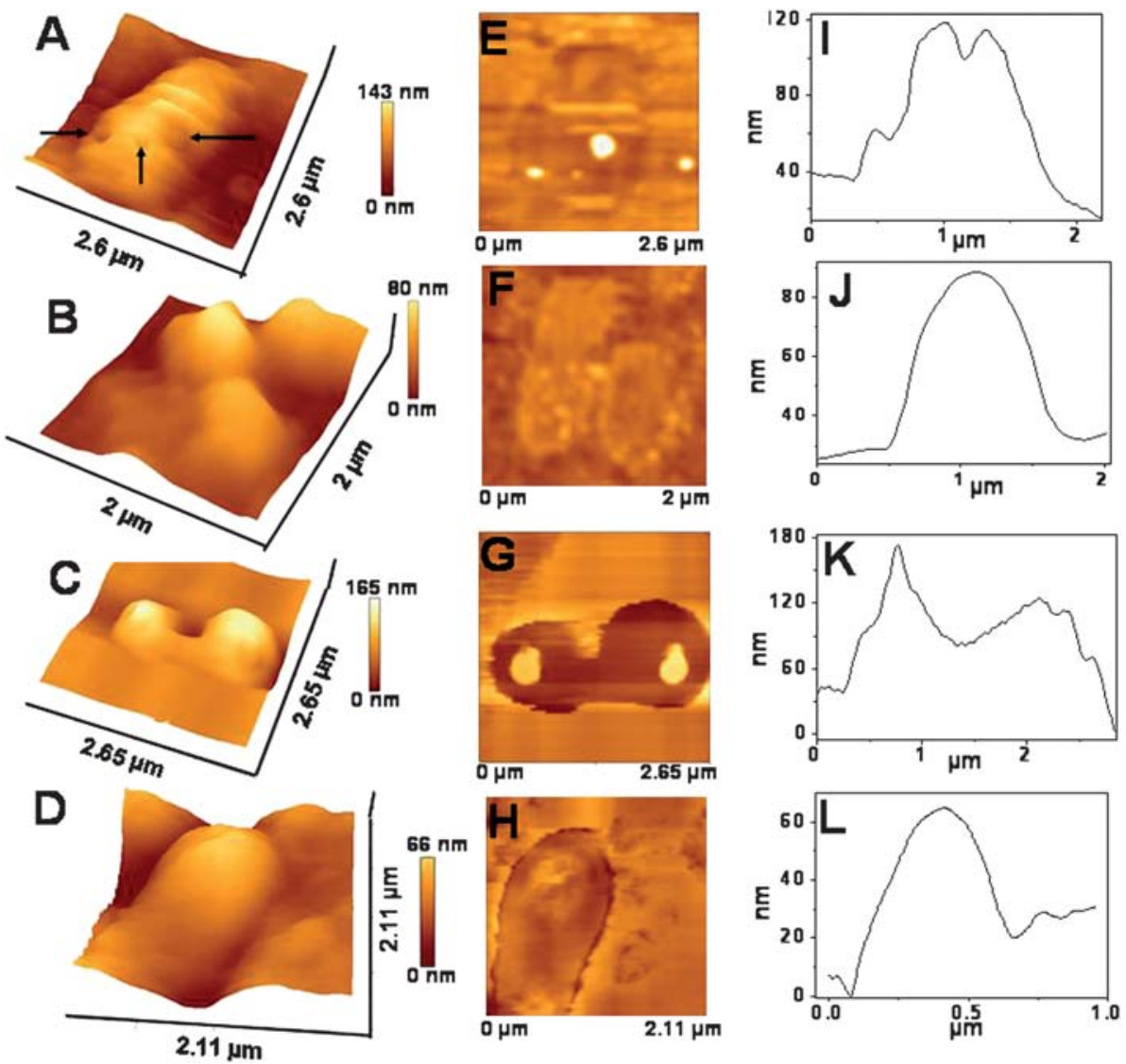

Fig. 6 Representative height mode AFM images of E. coli treated with cefaclor reduced gold nanoparticles (A), E. coli treated with cefaclor (B), E. coli treated with $\mathrm{NaBH}_{4}$ reduced gold nanoparticles (C) and plain E. coli without the treatment (D). The corresponding phase mode AFM images (E-H) and cross-sectional analysis (I-L) are shown. 

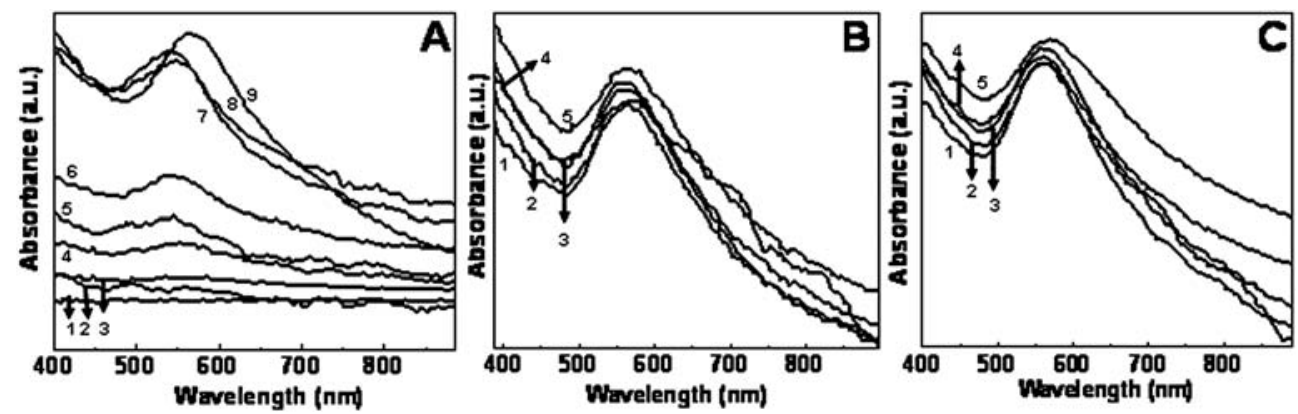

Fig. 7 (A) UV-vis spectra of cefaclor reduced gold nanoparticle films after coating at 0 min (curve 1), 30 min (curve 2), 60 min (curve 3), 2 h (curve 4), $4 \mathrm{~h}$ (curve 5), $6 \mathrm{~h}$ (curve 5), $8 \mathrm{~h}$ (curve 6), $22 \mathrm{~h}$ (curve 7) and $24 \mathrm{~h}$ (curve 8). Curve 9 corresponds to the UV-vis spectrum of the gold films after drying. (B and C) UV-vis spectra of gold films treated at pH 3 and 10 for 0 min (curve 1), $1 \mathrm{~h}$ (curve 2), $4 \mathrm{~h}$ (curve 2), $8 \mathrm{~h} \mathrm{(curve} \mathrm{3),} 12 \mathrm{~h}$ (curve 4 ) and $24 \mathrm{~h} \mathrm{(curve} \mathrm{5).}$

to the surrounding area, indicating the soft and fragile nature of the cell wall after treatment. E. coli treated with only gold nanoparticles showed bulge like structures on the surface of the cell wall, which could be gold nanoparticles that contrast with the smooth cell wall surface of E. coli (Fig. 6C and D). Crosssectional analysis shows an increase in height of $c a .53 \mathrm{~nm}$ from the bulge area to the smooth area of the bacteria, which is similar to the size of the gold nanoparticles used (Fig. $6 \mathrm{~K}$ and L). It may be possible that gold nanoparticles interact with the outer membrane of the bacteria that is composed of lipopolysaccharide and protein and deposit on the membrane (Fig. 6C and G) in accordance with the literature on the interaction of gold nanoparticles with lipopolysaccharide and protein. ${ }^{80-84}$ The deposited gold nanoparticles could slowly penetrate through porin channels of the membrane ${ }^{14,85}$ and/or diffuse through the membrane bilayer matrix ${ }^{86}$ and disrupt the membrane integrity, which could explain the low antibacterial activity of gold nanoparticles after 6 $\mathrm{h}$ of incubation.

The mechanism of enhanced antibacterial activity and advantages of cefaclor reduced gold nanoparticles can be explained as follows: (1) cefaclor reacts with the outer peptidogylcan layer of Gram-positive bacteria thereby increasing the membrane's porosity. Subsequently gold nanoparticles penetrate through the membrane and may be bound to the bacterial DNA, preventing DNA from unwinding and transcription occurring. ${ }^{13,14,87}$ Therefore, the combined action of cefaclor and $\mathrm{Au}$ nanoparticles leads to enhanced antibacterial activity. (2) In the case of Gram-negative bacteria, gold nanoparticles first diffuse through the membrane as described above and then cefaclor reacts with the inner peptidogylcan layer, promoting the formation of holes in the membrane. The penetration process and subsequent binding of gold nanoparticles to DNA result in a slower antibacterial effect as compared to the fast activity observed for Gram-positive bacteria. (3) Cefaclor reduced gold nanoparticles used after 5 days of synthesis showed $100 \%$ antibacterial activity, although pure cefaclor has a half-life of $c a .9 \mathrm{~h}$ with $11 \%$ activity in solution, ${ }^{88}$ indicating gold nanoparticles enhance the half-life and the activity of cefaclor. (4) Cefaclor and gold nanoparticles alone have low antibacterial effects compared to cefaclor reduced gold nanoparticles.

Further, we used cefaclor reduced gold nanoparticles to coat glass slides in order to obtain antimicrobial coatings. Cefaclor reduced gold nanoparticles were coated on poly(ethyleneimine) (PEI) functionalized glass surfaces at $\mathrm{pH} 5$. Amine molecules are often employed to functionalize surfaces to provide compatibility to biomolecules ${ }^{89}$ as amine containing polymers are known to interact strongly via physisorption on glass surfaces. ${ }^{89}$ Time dependent UV-vis spectra (Fig. 7) show that the intensity of the SPR band at $545 \mathrm{~nm}$ wavelength increases with increasing incubation time in gold nanoparticle solution, indicating the deposition of gold nanoparticles on the PEI coated surface as observed in the optical image of the glass slide (an inset of Fig. 8A). The saturation of adsorption was reached after $24 \mathrm{~h}$ of deposition without a substantial increase in the absorption intensity (curves 7 and 8, Fig. 7A). After drying of the gold film, a large red shift of $24 \mathrm{~nm}$ in SPR band position was observed due to aggregation of gold nanoparticles on the surface (curve 9, Fig. 7A).

Gold nanoparticle coated slides were treated under acidic $(\mathrm{pH}$ 3 ) and alkaline ( $\mathrm{pH} \mathrm{10)}$ conditions for $24 \mathrm{~h}$ to analyse the stability of the coatings. UV-vis spectra recorded as a function of time show that there is no change in the intensity of the absorption band, indicating strong binding of the gold nanoparticles to PEI functionalized surfaces (Fig. 7B and C). This result was concomitant with digital images where no significant visual changes in the colour of the slides were observed (insets of Fig. 8B and C). Gold nanoparticles interact with PEI surfaces via electrostatic interaction at $\mathrm{pH} 5$ as $\mathrm{PEI}$ is positively charged and gold nanoparticles are negatively charged at this $\mathrm{pH}$. AFM analysis showed that gold nanoparticles were uniformly deposited on PEI coated surfaces and the uniformity and integrity of gold films were not changed after treatment under different conditions (Fig. 8A-C).

The antibacterial activity of coated surfaces after treatment under adverse conditions showed that $E$. coli did not grow on the top surface of gold-coated slides (Fig. 8D and E). In contrast, a plain glass slide showed growth of bacteria on the surface (Fig. 8F). A clear zone of inhibition around the gold coated glass slides and the bacterial colony grown up around a plain glass slide can also be observed (Fig. 8D-F), indicating the effectiveness and maintenance of antimicrobial activity of surfaces after treatment under adverse conditions. This observation is supported by FTIR analysis that shows the characteristic signatures of cefaclor in the coated surfaces after treatment under adverse conditions (Fig. S5 $†$ ). The narrow zone of inhibition was due to the slow diffusion of cefaclor reduced gold nanoparticles in LB agar plate. The slow diffusion most probably occurred due to strong interaction of the amine coated surface with the cefaclor 

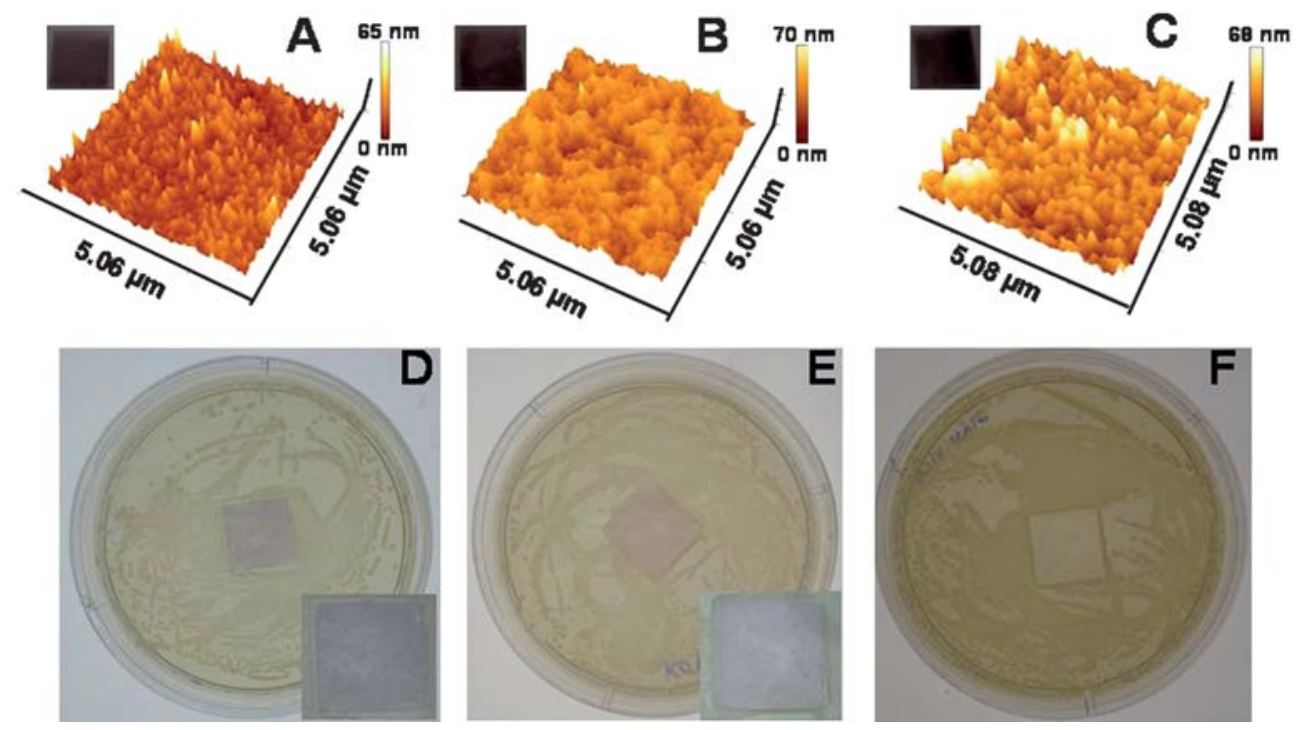

Fig. 8 3D-AFM images of cefaclor reduced gold nanoparticle films (A) and after treatment at $\mathrm{pH} 3$ (B) and $\mathrm{pH} 10$ (C). Insets of A-C correspond to digital images of gold films at different conditions, which were used to obtain AFM images. Antibacterial activity of gold slides treated at pH 3 (D), at pH 10 (E) and a bare glass slide (F) against E. coli. Insets of (D) and (E) demonstrate higher magnification images of gold slides present inside $E$. coli cultured Petri dishes to indicate clearly the zone of inhibition.

reduced gold nanoparticles. It may be possible that the gold nanoparticles protect the cefaclor from adverse conditions and/ or gold nanoparticles slowly diffuse inside the bacteria to kill them. We reused the gold coated glass slides 5 times and did not observe any growth of bacteria on top surface of coated glass surfaces (data not shown), indicating stability and long term usage of these slides for the coating purposes under adverse conditions.

\section{Conclusions}

In summary, we have described a simple way to synthesise spherical gold nanoparticles of size range from 52 to $22 \mathrm{~nm}$ using cefaclor (a second-generation $\beta$-lactam antibiotic) at different temperatures. The rate of reduction of gold ions in solution plays an important role in determining the size of the synthesized gold nanoparticles. The amine group of cefaclor acts as both a reducing and capping agent and therefore the antibacterial activity of cefaclor is preserved due to the presence of the free $\beta$ lactam ring being available on the surface of the nanoparticles. In this paper, we have shown that cefaclor reduced gold nanoparticles have potent antimicrobial activity on both Grampositive ( $S$. aureus) and Gram-negative bacteria (E. coli) compared to cefaclor and gold nanoparticles alone. Cefaclor inhibits the synthesis of the peptidoglycan layer, making cell walls porous and further the gold nanoparticles generate holes in the cell wall, resulting in the leakage of cell contents and cell death. It may also be possible that gold nanoparticles bind to the DNA of bacteria and inhibit the uncoiling and transcription of DNA thus promoting the death of bacteria. This paper also describes the fabrication of robust antimicrobial coatings on glass slides that retain their antimicrobial activity even under adverse conditions. The described procedure can further be used to coat a wide variety of surfaces for instance implants, fabrics for treatment of wounds and glass surfaces to maintain hygienic conditions in the home, in hospitals and other places.

\section{References}

1 D. Zhang, O. Neumann, H. Wang, V. M. Yuwono, A. Barhoumi, M. Perham, J. D. Hartgerink, P. Wittung-Stafshede and N. J. Halas, Nano Lett., 2009, 9, 666-671.

2 J. Won, M. Kim, Y.-W. Yi, Y. H. Kim, N. Jung and T. K. Kim, Science, 2005, 309, 121-125.

3 X. Wang and Y. Li, Chem. Commun., 2007, 2901-2910.

4 E. L. Que, D. W. Domaille and C. J. Chang, Chem. Rev., 2008, 108, $1517-1549$.

5 B. G. Trewyn, S. Giri, I. I. Slowing and S.-Y. V. Lin, Chem. Commun., 2007, 3236-3245.

6 H. Tsunoyama, H. Sakurai, N. Ichikuni, Y. Negishi and T. Tsukuda, Langmuir, 2004, 20, 11293-11296.

7 P. Migowski and J. Dupont, Chem.-Eur. J., 2007, 13, 32-39.

8 M. A. El-Sayed, Acc. Chem. Res., 2001, 34, 257-264.

9 P. Mulvaney, Langmuir, 1996, 12, 788-800.

10 W. P. McConnell, J. P. Novak, L. C. Brousseau, III, R. R. Fuierer, R. C. Tenent and D. L. Feldheim, J. Phys. Chem. B, 2000, 104, $8925-8930$.

11 R. Bhattacharya and P. Mukherjee, Adv. Drug Delivery Rev., 2008, 60, 1289-1306.

12 C. F. Shaw, Chem. Rev., 1999, 99, 2589-2600.

13 L. A. Baeur, N. S. Birenbaun and G. J. Meyer, J. Mater. Chem., 2004, 14, 517-526.

14 E. Katz and I. Willner, Angew. Chem., Int. Ed., 2004, 43, 6042-6108.

15 S. Mornet, S. Vasseur, F. Grasset and E. Duguet, J. Mater. Chem., 2004, 14, 2161-2175.

16 C. M. Niemeyer, Angew. Chem., Int. Ed., 2001, 40, 4128-4158.

17 M. Babic, A. M. Hujer and R. A. Bonomob, Drug Resist. Updates, 2006, 9, 142-156.

18 B. Helena, L. Andrea, J. Sylvia, M. P. Wolfgang, K. Janka, M. Peter and K. Milan, Int. J. Antimicrob. Agents, 1998, 10, 135-141.

19 H. C. Neu, Science, 1992, 257, 1064-1073.

20 M. Souli, B. W. Christine and M. E. George, Int. J. Antimicrob. Agents, 1998, 10, 23-30.

21 H. F. Chambers, Trends Microbiol., 2003, 11, 145-148.

22 H. C. Neu, Am. J. Med., 1985, 79, 2-13.

23 E. Fonze, M. Vanhove, G. Dive, E. Sauvage, J. M. Frere and P. Charlier, Biochemistry, 2002, 41, 1877-1885. 
24 J. Kant and D. G. Walker, in The Organic Chemistry of $\beta$-Lactames, ed. G. I. Georg, VCH, New York, 1993, p. 121.

25 J. D. Buynak, D. V. Ramana and G. Adam, Bioorg. Med. Chem Lett., 2000, 10, 853-857.

26 P. Kirkpatrick, Nat. Rev. Drug Discovery, 2006, 5, 284.

27 H. Gu, P. L. Ho, E. Tong, L. Wang and B. Xu, Nano Lett., 2003, 3, 1261-1263.

28 A. N. Grace and K. Pandian, Colloids Surf., A, 2007, 297, 63-70.

29 B. Saha, J. Bhattacharya, A. Mukherjee, A. K. Ghosh, C. R. Santra, A. K. Dasgupta and P. Karmarker, Nanoscale Res. Lett., 2007, 2, 614-622.

30 P. Li, J. Li, C. Wu, Q. Wu and J. Li, Nanotechnology, 2005, 16, 1912 1917.

31 M. J. Rosemary, I. MacLaren and T. Pradeep, Langmuir, 2006, 22, 10125-10129.

32 D. Nepal, S. Balasubramanian, A. Simonian and V. A. Davis, Nano Lett., 2008, 8, 1896-1901.

33 R. Jagannathan, P. Poddar and A. Prabhune, J. Phys. Chem. C, 2007, 111, 6933-6938.

34 G. Faundez, M. Troncoso, P. Navarrete and G. Figueroa, BMC Microbiol., 2004, 4, 19.

35 L. J. Wheeldon, T. Worthington, P. A. Lambert, A. C. Hilton, C. J. Lowden and T. S. J. Elliott, J. Antimicrob. Chemother., 2008, 62, 522-525.

36 R. Stone, Science, 2002, 298, 728-731.

37 M. F. Ilker, K. Nusslein, G. N. Tew and B. E. Coughlin, J. Am. Chem. Soc., 2004, 126, 15870-15875.

38 N. P. Desai, S. F. Hossainy and J. A. Hubbell, Biomaterials, 1992, 13, 417-420.

39 B. Dizman, M. O. Elasri and L. Mathias, J. Appl. Polym. Sci., 2004, 94, 635-642.

40 A. M. Klibanov, J. Mater. Chem., 2007, 17, 2479-2482.

41 J. Haldar, An. D. Q. Cienfuegos, J. Z. Chen and A. M. Klibanov, Proc. Natl. Acad. Sci. U. S. A., 2006, 103, 17667-17671.

42 K. Mukerjee, J. Rivera and A. M. Klibanov, Appl. Biochem. Biotechnol., 2008, 151, 61-70.

43 V. Decraene, J. Pratten and M. Wilson, Appl. Environ. Microbiol., 2006, 72, 4436-4439.

44 R. Bonnett, Chem. Soc. Rev., 1995, 24, 19-33.

45 S. Silver, FEMS Microbiol. Rev., 2003, 27, 341-353.

46 K. Page, M. Wilson and I. P. Parkin, J. Mater. Chem., 2009, 19, 3819 3831.

47 M. Strathmann and J. Wingerder, Int. J. Antimicrob. Agents, 2004, 24 234-240.

48 U. Samuel and J. P. Guggenbichler, Int. J. Antimicrob. Agents, 2004, 23, 75-S78.

49 M. E. Rupp, T. Fitzgerald, N. Marion, V. Helget, S. Puumala, J. R. Anderson and P. D. Fey, Am. J. Infect. Control, 2004, 32, 445-450.

50 D. Lee, R. E. Cohen and M. F. Rubner, Langmuir, 2005, 21, 96519659.

51 E. Ulkur, O. Oncul, H. Karagoz, E. Yeniz and B. Celikoz, Burns, 2005, 31, 874-877.

52 S. Link and M. A. El-Sayed, Annu. Rev. Phys. Chem., 2003, 54, 331366.

53 S. S. Shankar, A. Rai, A. Absar and M. Sastry, Chem. Mater., 2005, 17, 566-572.

54 A. Rai, A. Singh, A. Ahmad and M. Sastry, Langmuir, 2006, 22, 736741.

55 X. Sun, S. Dong and E. Wang, Mater. Chem. Phys., 2006, 96, 29-33.

56 N. Wangoo, K. K. Bhasin, S. K. Mehta and C. R. Suri, J. Colloid Interface Sci., 2008, 323, 247-254.

57 P.-L. Kuo, C.-C. Chen and M.-W. Jao, J. Phys. Chem. B, 2005, 109, 9445-9450.
58 P. R. Selvakannan, S. Mandal, R. Pasricha, S. D. Adyanthaya and M. Sastry, Chem. Commun., 2002, 1334-1335.

59 A. Aslam, L. Fu, M. Su, K. Vijaymohan and V. P. Dravid, J. Mater. Chem., 2004, 14, 1795-1797.

60 X. Peng, J. Wickman and A. P. Alivisatos, J. Am. Chem. Soc., 1998, 120, 5343-5344.

61 S. S. Shankar, S. Bhargava and M. Sastry, J. Nanosci. Nanotechnol., 2005, 5, 1721-1727.

62 Y.-S. Chiang and J. Turkevich, J. Colloid Sci., 1963, 18, 772-783.

63 J. Engelbrecht and H. Shyman, Gold Bull., 1983, 16, 66-69.

64 M. Mandal, S. K. Ghosh, S. Kundu, K. Esumi and T. Pal, Langmuir, 2002, 18, 7792-7797.

65 G. Madras and B. J. McCoy, J. Chem. Phys., 2002, 117, 8042-8050.

66 J. Polte, T. T. Ahner, F. Delissen, S. Sokolov, F. Emmerling, A. F. Thunemann and R. Kraehnert, J. Am. Chem. Soc., 2010, 132, 1296-1301.

67 T. Yamana and A. Tsuji, J. Pharm. Sci., 1976, 65, 1563-1574.

68 L. J. Lorens, F. N. Bachore and B. A. Olsen, J. Chromatogr. Sci., 1992, 30, 211-216.

69 R. R. Chauvehe, E. H. Flynn, B. G. Jackson, E. R. Lavagnino, R. B. Morin, R. A. Muller, R. W. P. Roeske, C. W. Ryan, J. L. Spencer and E. V. Heyningen, J. Am. Chem. Soc., 1962, 84, 3401-3402.

70 N. C. Nayak and K. Shin, J. Nanosci. Nanotechnol., 2006, 6, 35123516.

71 R. Bhattacharya, C. R. Patra, A. Earl, S. Wang, A. Katarya, L. Lu, J. N. Kizhakkedathu, M. J. Yaszemski, P. R. Greipp, D. Mukhopadhyay and P. Mukherjee, Nanomed: Nanotechnol., Biol. Med., 2007, 3, 224-238.

72 L.-H. Chen, A. Dudek, Y.-H. Lee and C.-H. Chang, Langmuir, 2007, 23, 3123-3127.

73 K. M. Mayya, A. Gole, N. Jain, S. Phadtare, D. Langevin and M. Sastry, Langmuir, 2003, 19, 9147-9154.

74 W. Bouhedja, G. D. Sockalingham, P. Pina, P. Allouch, C. Bloy, R. Labia, J. M. Millot and M. Manfait, FEBS Lett., 1997, 412, 39-42.

75 N. S. Sosnowska, A. Ocios and L. Fuks, J. Mol. Struct., 2006, 792793, 110-114.

76 M. Gil, J. L. Nunez, M. A. Palafox and N. Iza, Biopolymers, 2001, 62, 278-294.

77 V. Sambhy, M. M. MacBride, B. R. Peterson and A. Sen, J. Am. Chem. Soc., 2006, 128, 9798-9808.

78 P. K. Stoimenov, R. S. Klinger, G. L. Marchin and K. J. Klabunde, Langmuir, 2002, 18, 6679-6686.

79 M. Meinchen, D. L. Holroyd and M. Rautenbach, Antimicrob. Agents Chemother., 2005, 49, 4085-4092.

80 A. Verma, O. Uzun, Y. Hu, Y. Hu, H.-S. Han, N. Watson, S. Chen, D. J. Irvine and F. Stellacci, Nat. Mater., 2008, 7, 588-595.

81 P. He and X. Zhu, Mater. Res. Bull., 2007, 42, 1310-1315.

82 A. S. Urban, M. Fedoruk, M. R. Horton, J. O. Radler, F. D. Stefani and J. Feldmann, Nano Lett., 2009, 9, 2903-2908.

83 N. Wangoo, C. R. Suri and G. Shekhawat, Appl. Phys. Lett., 2008, 92, 133104.

84 J. Chen, J. A. Hessler, K. Putchakayala, B. K. Panama, D. P. Khan, S. Hong, D. G. Mullen, S. C. DiMaggio, A. Som, G. N. Tew, A. N. Lopatin, J. R. Baker, M. M. Banaszak Holl and B. G. Orr, J. Phys. Chem. B, 2009, 113, 11179-11185.

85 H. Nikaido and M. Vaara, Microbiol. Rev., 1985, 49, 1-32.

86 J. S. Chapman and N. H. Geogopapadakou, Antimicrob. Agents Chemother., 1988, 32, 438-442.

87 K. I. J. Batarsch, J. Antimicrob. Chemother., 2004, 54, 546-548.

88 F. M. MacKenzie, K. E. Milne and I. M. Gould, Int. J. Antimicrob. Agents, 2004, 23, 337-342.

89 J. Song, J. Chen, C. M. Klapperich, V. Eng and C. R. Bertozzi, J. Mater. Chem., 2004, 14, 2643-2648. 